\title{
Ground Motion Prediction for Regional Seismic Risk Analysis Including Nuclear Power Station
}

\author{
Hiroyasu Abe
}

\begin{abstract}
Ground motion simulation is one of techniques used to analyze seismic risk due to damage of structure and its effects on society. In this paper, the ground motion simulation using fault plane is used. Recently, ground motion simulation using fault model have been widely applied. Characterized fault model is conveniently used to model the heterogeneous slip distribution on fault plane, which divide the fault into two areas (asperity area and background area). More detailed model is needed to conduct probabilistic seismic risk assessment, which incorporate uncertainty in ground motion prediction. The model, however, is too simplified to model the complex characteristics of slip. In this paper, a stochastic model to simulate the slip distribution of fault plane is proposed for that purpose.
\end{abstract}

Keywords Seismic motion - Random field - Crustal earthquake - Fault model • Earthquake ground motion

\section{Introduction}

To discuss the safety of critical infrastructure such as nuclear power plants, seismic risk assessment is conducted. Usually engineered system consists of several facilities which are spatially distributed. Though the conventional risk assessment is mainly for a single facility, risk assessment for multi-facility is required. An example of spatially distributed system is a nuclear power station. In a nuclear site, several units are located. Additionally, sometimes several sites are located closely each other. For public, the information on the likelihood and possible amount of radioactive material release is needed and all the units may suffer from identical external events, multi-unit risk assessment is necessary. For that purpose, a technique to simulate spatially distributed ground motion probabilistically is needed.

\footnotetext{
H. Abe $(\bowtie)$

Department of Nuclear Engineering and Management, The University of Tokyo,

Tokyo, Japan

e-mail: h.abe.ju95th@gmail.com

(C) The Author(s) 2017

J. Ahn et al. (eds.), Resilience: A New Paradigm of Nuclear Safety,

DOI 10.1007/978-3-319-58768-4_17
} 
Recently, ground motion simulation using fault model is widely used for ground motion simulation for a single site. In the fault model, a simplified characterized fault model was proposed and used for that purpose, and standardized method, e.g., 'recipe' [3], is proposed. The method, however, was proposed to calculate the average characteristics of ground motion. More detailed model is needed to conduct probabilistic seismic risk assessment, which incorporate uncertainty in ground motion prediction. Therefore, in this study, a probabilistic modeling of slip distribution focusing on crustal earthquake is proposed.

\section{A Proposed Model to Simulate the Slip Distribution}

Figure 1 is an example of actual slip distribution in the fault plane of West Off Fukuoka Earthquake in 2005. The spatial distribution of slip displacement exhibits stochastic characteristics. When two elements in the fault plane is closely located, slip displacement is similar, i.e., correlated. On the other hand, slip displacement is random when two elements are distant. These characteristics of slip displacement can be modeled using the spatial correlation model.

This correlation structure of the slip distribution is analyzed. The slip displacement at each element at Fig. 1 is denoted $y=\left\{y_{1}, \ldots, y_{n}\right\}$, where $n$ is the number of element. Slip displacement is assumed to be distributed by the log normal distribution. Table 1 shows the average and standard deviation of logarithm of slip $y$ in Fig. 1 obtained by the maximum likelihood estimate. Then, the correlation structure from slip distribution during actual earthquake is analyzed. Semivariogram $r$ is used for that purpose. $r\left(Y_{i}, Y_{j}\right)$ is defined as follows:

Fig. 1 Slip distribution along fault surface of West Off Fukuoka Earthquake [1, 4]

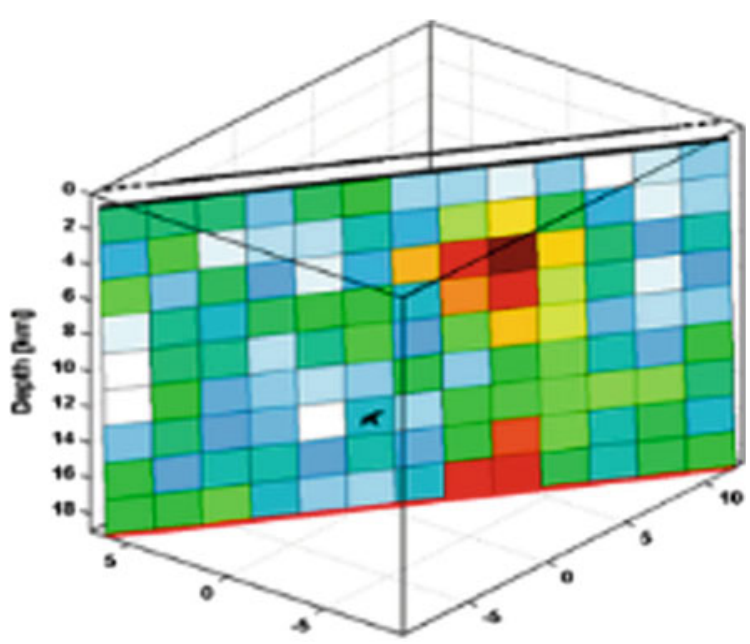


Table 1 Average and standard deviation of logarithmic slip of West Off Fukuoka Earthquake

\begin{tabular}{l|l}
\hline Average & Standard deviation \\
\hline 3.90 & 0.87 \\
\hline
\end{tabular}

$$
r\left(Y_{i}, Y_{j}\right)=\frac{1}{2} E\left[\left(Y_{i}-Y_{j}\right)\right]^{2}
$$

where, $Y_{i}$ and $Y_{j}$ are the lengths of slip at the $i$-th and $j$-th element respectively.

And, semivariogram ' $r(Y i, Y j)$ ' is defined as follows:

$$
r\left(Y_{i}, Y_{j}\right)=\sigma_{Y}^{2} \times\left(1-\rho_{Y i Y_{j}}\right)
$$

where, $\sigma_{Y}$ is standard deviation of fault plane and $\rho_{Y i Y j}$ is the correlation coefficient between $Y i$ and $Y j$.

In this study, this correlation is assumed to depend on $\mathrm{h}$ that is distance between two elements, and the correlation coefficient is defined as follows:

$$
\mathrm{r}(\mathrm{h})=\frac{1}{2 N(h)} \sum_{i=1}^{N(h)}\left(Y\left(\mathbb{X}_{1 i}\right)-Y\left(\mathbb{X}_{2 i}\right)\right)^{2}
$$

Provided that $N(h)$ is the number of pairs that fulfill (4) include $\left(\mathbb{X}_{1 i}, \mathbb{X}_{2 i}\right)$.

$$
\mathrm{h}-\frac{\Delta h}{2} \leqq\left|\mathbb{X}_{1 i}-\mathbb{X}_{2 i}\right| \leqq h+\frac{\Delta h}{2}
$$

where, $\Delta \mathrm{h}$ is assumed $1.34 \mathrm{~km}$. Figure $2 \mathrm{a}$ is $r(h)$ obtained from Eq. (3). Figure $2 \mathrm{~b}$ shows $N(h)$ for each bin. In Fig. 2a, fitted parabola that is determined from least-squares method is denoted.

Fig. 2 Semivariogram showing spatial correlation of slip obtained from slip distribution during West Off Fukuoka Earthquake
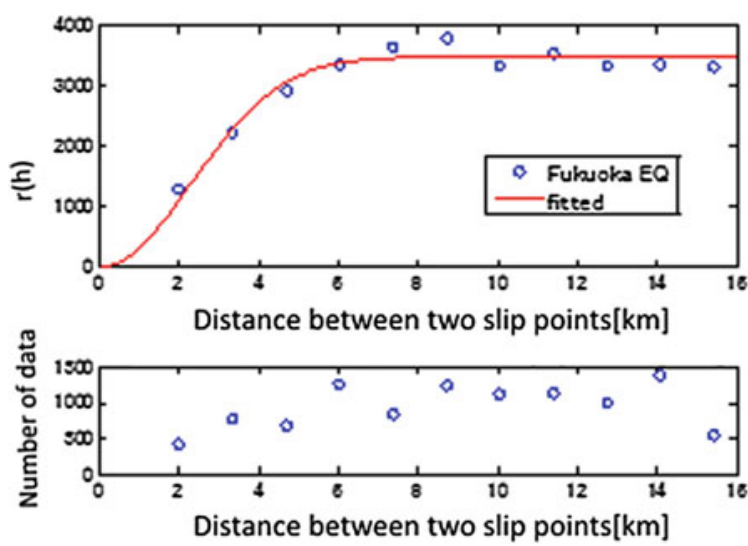


$$
r(h)=b\left(1-\exp \left(-a h^{2}\right)\right)
$$

where, $b$ is the constant equal to the dispersion $\sigma_{Y}^{2}$. $a$ is estimated 0.0947 , and $\mathrm{b}$ is $3.4819 \times 10^{3}$.

Simulation of slip distribution in fault plane is conducted by Monte Carlo Simulation. The slip of fault plane in $i$-th element is $Y_{i} . Y=\left[Y_{1}, Y_{2}, \ldots, Y_{N}\right]^{\prime}$. $Y$ follows logarithmic normal distribution. $W$ is the normal random variable that is transformed from $Y$ by Rosenblatt conversion as follows:

$$
W=\Phi^{-1}(F(Y))
$$

where $\Phi^{-1}()$ is cumulative function of standard normal distribution, and $F(Y)$ is the cumulative distribution function of $Y$.

$Z$ is decided by random number, and $W$ is determined from that.

$$
W=\Phi_{w} Z
$$

$W$ is determined from that. In this equation, $Z$ is the stochastic variable vector that fulfill normal distribution, mean of 0 and standard deviation of $1 . \Phi_{W}$ is Eigenvector of covariance ' $C_{W W}$ '. (8)

$$
C_{W W} \Phi_{W}=\Phi_{W} \Lambda_{W}
$$

$\Lambda_{W}$ is the square matrix, diagonal element is characteristic number and the other is 0 .

$$
C_{W W}=\left[\begin{array}{ccc}
\rho_{11} & \cdots & \rho_{N 1} \\
\cdot & & \cdot \\
\cdot & & \cdot \\
\rho_{N 1} & \cdots & \rho_{N N}
\end{array}\right]
$$

In this equation, $\rho_{W i W j}$ is correlation coefficient between $W i$ and $W j$. In this study, it is premised that $\rho_{W i W_{j}}$ is equal to $\rho_{Y i Y j}$, and fulfill (5). So, it is premised that $\rho_{Y i Y j}$ is a function of only $h_{i j}$ which is distance between $i$ and $j$.

$$
\rho_{Y i Y j}=\exp \left(-a h_{i j}^{2}\right)
$$

Distribution in fault is simulated under the condition of $M w 6.6$ $\left(M_{0}=9.0 \times 10^{18} \mathrm{~N} \cdot \mathrm{m}\right)$ that is same as West Off Fukuoka Earthquake. 
Fig. 3 Geometrical relation between fault plane and receiver locations $(\mathrm{A}$ and $\mathrm{B})$

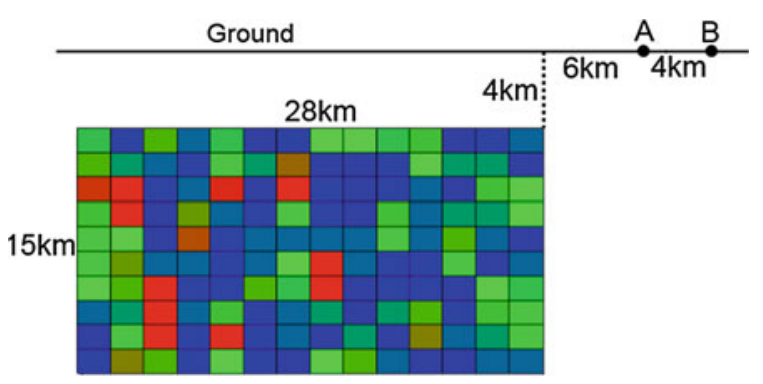

\section{Ground Motion Simulation Using Proposed Model}

Stochastic Green's function [2] method is used for ground motion simulation. The fault geometry and receiver location is showed in Fig. 3. S-wave velocity on surface is assumed to be $400 \mathrm{~m} / \mathrm{s}$ in this study.

In Fig. 4a, samples of slip distribution is shown, while simulated ground motion (velocity time history) for respective case is shown in Fig. 4b. As shown in the figure, the temporal characteristics of velocity time history are different between samples. Maximum velocity increases if large slip appear between the hypocenter and the receiver as shown in the bottom figure in Fig. 4.

The simulated slip distribution was closer to real distribution than characterized fault model. However, the long slip area is scattered than actual case.

\section{Conclusions}

Multi-unit and multi-site probabilistic seismic risk assessment is needed to respond to the public concerns about offsite emergency response. In this paper, a stochastic fault rupture model is proposed for the purpose of multi-unit and multi-site probabilistic seismic risk assessment.

The simulated slip distribution was closer to real distribution than characterized fault model. However, the larger slip area scattered than actual case. It is needed to be improved in future study. For example, it would be needed that slip distribution is modeled by a different approach.

Acknowledgements This work is supervised by Professors Naoto Sekimura and Tatsuya Itoi. 
(a)Slip Distribution
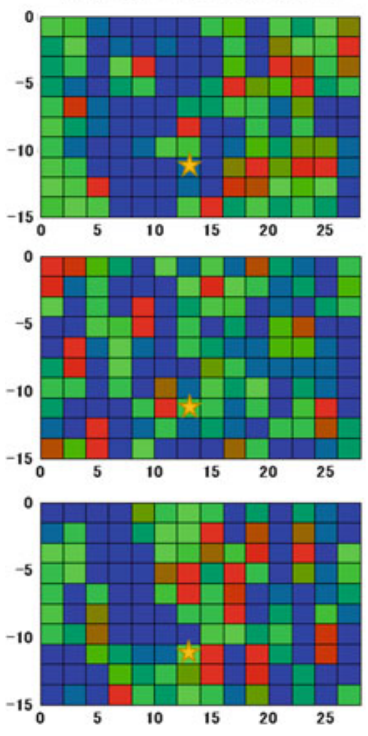

(b) Velocity at A
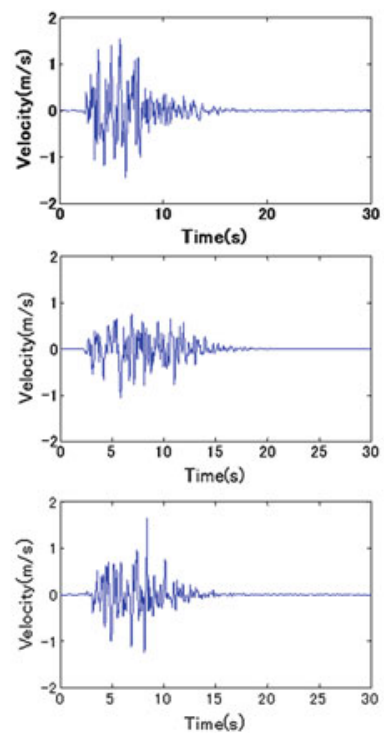

(c) Velocity at B
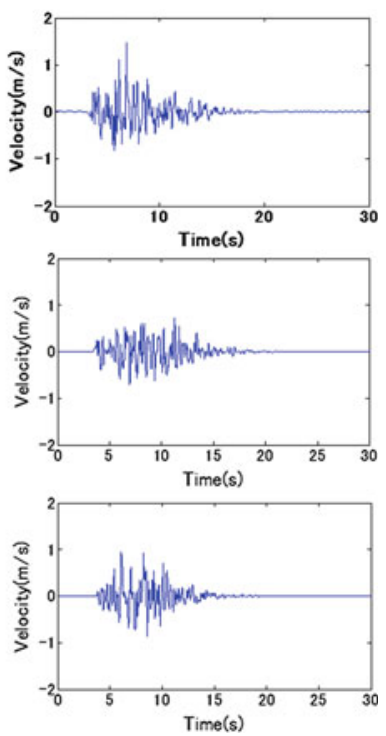

Fig. 4 Distribution slip and velocity of ground motion obtained by MCS

\section{References}

1. K. Asano, T. Iwata, Source process and near-source ground motions of the 2005. West Off Fukuoka Prefecture earthquake. Earth Planets Space 58, 93-98 (2006)

2. D.M. Boore, Stochastic simulation of high-frequency ground motions based on seismological models of the radiated spectra. Bull. Seism. Soc. Am. 73(6), 1865-1894 (1983)

3. Headquarter for Earthquake Research Promotion: Recipe for Predicting Strong Ground Motion by a fault plane of earthquake (2009). (In Japanese)

4. P.M. Mai, Finite-Source Rupture Model Database. http://equake-rc.info/SRCMOD/. Accessed $28 \mathrm{Feb} 2015$ 
Open Access This chapter is licensed under the terms of the Creative Commons Attribution 4.0 International License (http://creativecommons.org/licenses/by/4.0/), which permits use, sharing, adaptation, distribution and reproduction in any medium or format, as long as you give appropriate credit to the original author(s) and the source, provide a link to the Creative Commons license and indicate if changes were made.

The images or other third party material in this chapter are included in the chapter's Creative Commons license, unless indicated otherwise in a credit line to the material. If material is not included in the chapter's Creative Commons license and your intended use is not permitted by statutory regulation or exceeds the permitted use, you will need to obtain permission directly from the copyright holder.

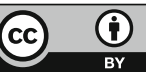

